\title{
A nondestructive molecule extraction method allowing morphological and molecular analyses using a single tissue section
}

\author{
Wei-Sing Chu ${ }^{1,3}$, Qi Liang ${ }^{1}$, Jilan Liu ${ }^{1}$, Min Qi Wei ${ }^{1}$, Mary Winters ${ }^{2}$, Lance Liotta ${ }^{2}$, \\ Glenn Sandberg ${ }^{1}$ and Maokai Gong ${ }^{3}$ \\ ${ }^{1}$ Department of Scientific Laboratories, Armed Forces Institute of Pathology, Washington, DC, USA; \\ ${ }^{2}$ Proteomics Laboratory, Laboratory of Pathology, NIH/NCI, Bethesda, MD, USA and ${ }^{3}$ Bio-Quick Inc., \\ Silver Spring, MD, USA
}

\begin{abstract}
In clinical practice, molecular analysis of tumor specimens is often restricted by available technology for sample preparation. Virtually all current methods require homogenization of tissues for molecule extraction. We have developed a simple, rapid, nondestructive molecule extraction (NDME) method to extract proteins and nucleic acids directly from a single fixed or frozen tissue section without destroying the tissue morphology. The NDME method is based upon exposure of micron-thick tissue section to extraction buffer with the help of heating and/or intact physical forces (ultrasound and microwave) to facilitate release of macromolecules into the buffer. The extracted proteins and nucleic acids can be used directly without further purification for downstream SDS-PAGE analysis, immunoblotting, protein array, mass spectra protein profiling, PCR, and RTPCR reactions. Most importantly, the NDME procedure also serves as an antigen retrieval treatment, so that after NDME, the same tissue section can be used for histopathological analyses, such as H\&E staining, immunohistochemistry, and in situ hybridization. Thus, the NDME method allows, for the first time, both histological diagnosis and molecular analysis on a single tissue section, whether it is from frozen or fixed tissue specimens.
\end{abstract}

Laboratory Investigation (2005) 85, 1416-1428. doi:10.1038/labinvest.3700337; published online 22 August 2005

Keywords: molecule extraction; tissue section; immunohistochemistry; pathological diagnosis; molecular analysis

As the human genome project nears completion, the focus of research is shifting to the immense tasks of identifying the structures, functions, and interactions of proteins produced by individual genes, and determining their roles in cancers and other diseases. ${ }^{1-3}$ Analysis of tissue proteins and mRNA transcripts is limited by the current technologies for preserving clinical specimens. Traditional formalinfixed, paraffin-embedded (FFPE) specimens provide superior morphology and easy long-term storage of clinical specimens. However, FFPE specimens are not always compatible with current molecular techniques due to suboptimal recovery of most macromolecules.

Owing to these extraction problems, frozen tissue is preferred for molecular research. However, large-

Correspondence: Dr W-S Chu, MD, Department of Scientific Laboratories, Armed Forces Institute of Pathology, Washington, DC 20306-6000, USA.

E-mail: chu@afip.osd.mil

Received 6 May 2005; revised 1 July 2005; accepted 6 July 2005; published online 22 August 2005 scale processing and storage of frozen tissue are impractical and expensive. In the routine practice of pathology, the need for superior morphology provided by FFPE outweighs the need for molecular diagnosis. This situation becomes even more problematic with limited biopsies. Therefore, a method that could efficiently extract high-quality proteins and nucleic acids in sufficient quantities to perform any number of molecular diagnostic methods, while providing optimal morphology from FFPE tissue, would provide the ideal solution to many of these problems.

All currently available molecule extraction methods require the homogenization or destruction of tissues, fixed or fresh, such that multiple specimens must be prepared for both molecular analysis and histological diagnosis. ${ }^{4-6}$ It is extremely difficult to extract macromolecules from FFPE clinical specimens due to crosslinking between proteins and nucleic acids. Clark and Damjanov ${ }^{4}$ reported in 1986 that keratin proteins could only be extracted from placental tissues frozen at $-30^{\circ} \mathrm{C}$ or fixed in Carnoy's solution, but not from formalin-fixed 
tissues. Proteins from tissues fixed in noncrosslinking fixatives, such as acetone, alcohol or Carnoy's solution, could be readily extracted and analyzed by SDS-PAGE, Coomassie blue staining, and immunoblotting. ${ }^{7-8}$ However, similar extraction treatment for formalin-fixed tissues generated no detectable bands in Coomassie blue-stained gels and very low amounts of highly degraded bands detectable by polyclonal antibody. ${ }^{5}$ These observations led investigators to suspect that formalin fixation may destroy macromolecules and may not preserve tissues as well as other noncross-linking fixatives. In the early 1990s, several groups reported that DNA and RNA remained well preserved in FFPE and could be extracted for PCR amplification, although the mRNA size would be substantially reduced. ${ }^{9-12}$ Only recently have researchers succeeded in developing protein extraction methods for FFPE tissues. ${ }^{6,13-15}$ However, these processes are destructive and require several hours, substantial amounts of tissues, and high salt concentrations in order to achieve satisfactory protein yields for SDS-PAGE analysis.

We have developed a simple, rapid, NDME method to extract proteins and nucleic acids directly from fixed or unfixed tissue section slides without destroying the tissue section. Studies in our laboratory of over 500 samples of various tissues have shown that the NDME technology not only extracts high amounts of soluble proteins and DNA/ RNA from a single FFPE tissue section but also maintains the integrity of the tissue morphology and antigenicity after extraction. Three potential applications of NDME are: (1) simultaneous proteomic and genomic studies and histological analysis, including $\mathrm{H} \& \mathrm{E}$, IHC, and ISH for difficult clinical cases; (2) performance of retrospective studies of many diseases, particularly those that we do not currently encounter; and (3) identification of relationships between levels of disease-perturbed proteins and response to drug therapy, ultimately allowing clinicians to not only provide a morphologic diagnosis but also to determine which therapy will yield the greatest response.

\section{Materials and methods}

\section{Tissue Selection and Preparation}

FFPE tissues and frozen tissues from brain, breast, heart, pancreas, liver, lung, spleen, lymph node (LN), colon, and prostate were chosen for development and testing of the NDME method. The storage age of selected FFPE $\mathrm{H}+\mathrm{E}$ or unstained sections ranged from 3 months to 50 years. Before the extraction treatment, FFPE sections were deparaffinized by a 2-min immersion in xylene for five rounds, $100 \%$ alcohol twice, $95 \%$ alcohol to rehydrate, and then air-dried at room temperature for $5 \mathrm{~min}$.

\section{Protein and RNA Extraction}

We previously tested tissue-PE LB buffer from Geno Tech Inc. (St Louis, MO, USA), $1 \mathrm{mM}$ EDTA and $0.01 \mathrm{M}$ sodium citrate (two commonly used antigen retrieval solutions), and NDME-PE (optimal for protein extraction), NDME-NE (optimal for nucleic acid extraction), and NDME-U (for protein and nucleic acid extraction) extraction buffers from BioQuick Inc. (Silver Spring, MD, USA), for extraction efficiency. Depending on the size of the tissue section, $10-100 \mu \mathrm{l}$ of extraction buffer is added to the deparaffinized slide section with a snap-on coverslip manufactured by Bio-Quick Inc. (Silver Spring, MD, USA). As shown in Figure 1, the slide section assembly is placed in an NDME device (BioQuick Inc.), heated with high humidity at $100^{\circ} \mathrm{C}$ for 5-30 min, and immediately cooled to $4^{\circ} \mathrm{C}$. The extract is collected from the slide through the center hole on the coverslip and used without further purification for gel-based protein analysis and PCR, or stored at $-70^{\circ} \mathrm{C}$ for future use. For RNA analysis, the extract is treated with DNase I, denatured, reverse transcribed into first-strand cDNA, and then PCR amplified. For successful morphological studies on slides, it is important to avoid the slide sections being dry during the extraction. After extraction, the slide is submerged in PBS buffer for histological diagnosis such as H\&E, IHC, CISH, and FISH studies. Otherwise, the slides are processed as normal FFPE slides for long-term storage.

\section{IHC Staining}

NDME extraction also achieves antigen retrieval on slide section so that IHC staining can be directly carried out on slide section after NDME procedures. IHC staining carried out on slide sections without NDME may require antigen retrieval procedures according to conventional protocols. To block endogenous peroxidase and unspecific protein binding, slides are treated with $3 \% \quad \mathrm{H}_{2} \mathrm{O}_{2}$ for $10 \mathrm{~min}$ and $10 \%$ bovine serum albumin for $20 \mathrm{~min}$ at RT, respectively, before being incubated with antibodies against prostatic acid phosphatase (PAP), prostate-specific antigen (PSA), Her-2, ER, cyclin E, CEA, LCA, CD5, cytokeratin, CD20, CD30, and HIV p24 at various dilutions. After they are washed in PBS, all slides are incubated with either anti-mouse or anti-rabbit secondary antibody conjugated biotin at RT for half an hour. After being washed in PBS, all slides are incubated with ABC kit for half an hour at $\mathrm{RT}$. The development is then carried out with DAB substrate (Dako, Carpinteria, CA, USA). Negative controls include staining without primary antibodies or use of irrelevant primary antibodies.

\section{CISH and ISH Staining}

ISH staining is carried out directly on slides after NDME treatment. Fluorescein isothiocyanate (FITC)- 


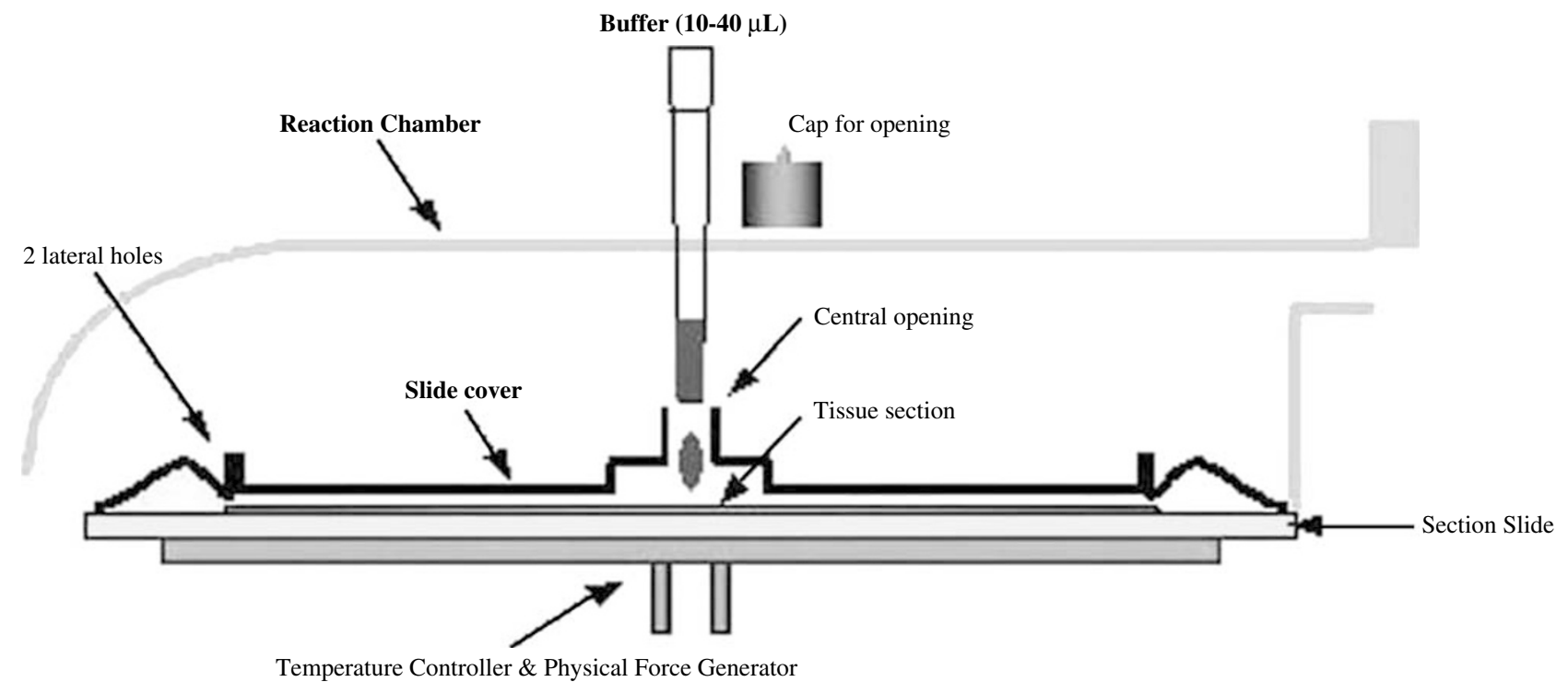

Figure 1 Schematic of the NDME device. The device can extract sufficient macromolecules for proteomic and genomic analysis from a single tissue section of $3-25 \mathrm{~mm}^{2} \times 5 \mu \mathrm{m}$ without destroying tissue morphology.

labeled probes (BioGenex, San Ramon, CA, USA) specific for mRNA of EBER, kappa and lambda immunoglobulin are applied to the tissue section, covered by a coverslip, and denatured at $100^{\circ} \mathrm{C}$ for $5 \mathrm{~min}$ in a steamer. Slides are allowed to cool and hybridize with the probe at RT for $1 \mathrm{~h}$. Sections are washed twice for $3 \mathrm{~min}$ each in $2 \times \mathrm{SSC}$, incubated for $30 \mathrm{~min}$ with monoclonal mouse anti-FITC, followed by two washes in PBS for 3 min each. The tissue section is incubated with biotinylated secondary antibody for $30 \mathrm{~min}$ at RT followed by two 3-min washes in PBS, and then incubated with streptavidin-biotinylated peroxidase for $30 \mathrm{~min}$. After PBS washing, the slide is treated with 5-bromo-4-chloro3-indolyl phosphate/nitroblue tetrazolium reagents for color development. Appropriate positive and negative controls provided by BioGenex are used with each reaction. c-Myc translation CISH staining is performed according to instructions provided by Zymed Inc. (South San Francisco, CA, USA).

\section{SDS-PAGE and Western Blot}

In all, $1-5 \mu \mathrm{g}$ of protein or $20 \mu \mathrm{l}$ of extract are mixed with SDS-PAGE loading buffer at a final concentration of $65 \mathrm{mM}$ Tris, $5 \% 2$-mercaptoethanol, $3 \%$ SDS, $10 \%$ glycerol, and bromophenol blue, denatured at $70^{\circ} \mathrm{C}$ for $10 \mathrm{~min}$, and applied to a $4-15 \%$ gradient NuPAGE gel (Invitrogen, Carlsbad, CA, USA). After electrophoresis, the gel is removed and stained by silver staining or Coomassie blue according to the manufacturer's instruction (Bio-Rad Laboratories, Hercules, CA, USA) to visualize distribution of extracted macromolecules (proteins only for Coomassie staining and proteins and DNA/RNA for silver staining).
For Western blot analysis, the SDS-PAGE gel is transferred after separation onto a polyvinylidene difluoride (PVDF) membrane (from Bio-Rad) in transfer buffer containing $192 \mathrm{mM}$ glycine, $25 \mathrm{mM}$ Tris-HCI, pH 8.3, 20\% (v/v) methanol, and $0.02 \%$ SDS at $100 \mathrm{~V}$ for $1 \mathrm{~h}$. The membrane is washed once with TBS buffer $(50 \mathrm{mM}$ Tris-HCl, $\mathrm{pH} 7.5$ and $150 \mathrm{mM} \mathrm{NaCl}$ ) and blocked $1 \mathrm{~h}$ to overnight in TBS buffer with $5 \%$ milk at RT with constant shaking. The membrane is then incubated with primary antibody at RT for $1 \mathrm{~h}$, washed three times with TTBS (TBS plus $0.1 \%$ Tween-20), and incubated for $1 \mathrm{~h}$ with peroxidase or alkaline phosphatase-conjugated anti-IgG antibody. After washing with TTBS three times, the membrane is treated with LumiGLO Elite or AP Color Development kits (KPL, Gaithersburg, MD, USA) to visualize protein bands.

\section{Reverse-Phase Protein Arrays}

This method of proteomic analysis was described previously by Paweletz et al. ${ }^{16}$ Briefly, tissue extracts are arrayed onto nitrocellulose-coated FAST slides (Schleicher and Schuell, Keene, NH, USA). Each sample is spotted in a serial 1:2 dilution curve with duplicates of each dilution. Extraction buffer alone is spotted as a negative control. Slides are prepared for signal development by incubating for 10 min in a $10 \%$ solution of Mild Re-Blot Plus, followed by incubation in I-Block, a casein-based blocking solution, for at least $1 \mathrm{~h}$. Signal is developed using the CSA system based on enzymemediated deposition of biotin-tyramide conjugates at the site of a biotinylated antibody-ligand complex. Arrays are analyzed with ImageQuant version 5.2 software (Molecular Dynamics, Amersham, UK). 
Spot intensity after background correction is proportional to the concentration of the target protein. ${ }^{16}$ Total protein is similarly determined after staining with Sypro Ruby, and is used to normalize for protein loading.

\section{SELDI-TOF MS}

Proteins in the NDME extracts are purified and enriched using a hydrophobic reverse-phase chip (H4) from Ciphergen Biosystems (Freemont, CA, USA). The chip is prepared by placing $2 \mu \mathrm{l}$ of acetonitrile on the spot. Just before the acetonitrile evaporates completely, $2 \mu \mathrm{l}$ of protein extracts are applied to the surface. The chip is incubated at high humidity for $20 \mathrm{~min}$ to allow the protein sample to interact with the surface. After incubation, the chip is washed five times with $5 \mu \mathrm{l}$ of $30 \%$ acetonitrile and allowed to air dry. To each protein-bound chip spot, $1 \mu \mathrm{l}$ of saturated sinapinic acid dissolved in $50 \%$ acetonitrile and $0.5 \%$ trifluoracetic acid is added to cocrystallize with the bound proteins. The chip is then transferred into the chip reader of the Protein Biology System 1 SELDI-TOF mass spectrometer (PBS-II) to measure the molecular weights (MW) of bound proteins according to an automated data collection protocol. Data interpretation is augmented by the use of ProteinChip software v2.0.

\section{RT-PCR Analysis of $\beta$-Actin mRNA Fragments}

$\beta$-Actin and fibrinogen genes are chosen and amplified because their gene products exist in all cells. Primers to generate amplicons ranging from 150 to over $1000 \mathrm{bp}$ are synthesized. PCR and RTPCR are performed according to Super Script III Reverse Transcriptase and Taq polymerase from Invitrogen (Carlsbad, CA, USA). PCR reaction, along with appropriate controls, usually entails 30-40 amplification cycles. PCR products are separated on a $2 \%$ agarose gel stained with ethidium bromide.

\section{Results}

\section{The NDME Device}

The prototype for the NDME procedure was developed by Bio-Quick Inc. (Silver Spring, MD, USA) and includes temperature and humidity control, and optional implementation of ultrasound or microwave for improved extraction efficiency. In this paper, we describe an NDME procedure using temperature control, without the use of ultrasound or microwave. As shown in Figure 1, the NDME device has a reaction chamber that can apply multiple physical forces, a snap-on slide coverslip, and buffer systems as chemical forces for molecule extraction. High humidity and high temperature, along with agitation induced by ultrasound and microwave, can be applied in the reaction chamber.
A slide cover secured to the slide is designed to hold a thin layer of extraction buffer over the tissue section. The slide cover has a central hole for addition and retrieval of extraction buffer, and two lateral holes for air exchange. After approximately $20 \mathrm{~min}$ of heating and cooling in the reaction chamber, the extraction solution is removed from the slide. The extract is used for downstream protein and DNA/RNA analyses, while the tissue section is ready for morphological analyses.

\section{NDME Extracts both Proteins and Nucleic Acids from FFPE Tissues}

Using SDS-PAGE, we compared total molecules extracted from FFPE sections using various extraction buffers. Coomassie blue staining detects protein, but not DNA/RNA, at the level of $0.3-1 \mu \mathrm{g} /$ band, while silver staining detects both protein and DNA/RNA with a much higher sensitivity (2 ng/ band). As shown in Figure 2a, NDME-PE (lane B) extracted a significantly greater amount of proteins than other buffers (lanes X, E, C, and P). A greater number of high-MW species were observed with silver staining than with Coomassie blue staining, indicating the presence of a large amount of nucleic acids in the solution. As expected, the amount of proteins extracted from tissue sections is also affected by whether the tissue is fresh or formalin fixed (Figure 2b). Usually, about 5-10 $\mu \mathrm{g}$ total proteins and $0.1-0.3 \mu \mathrm{g}$ total nucleic acids were extracted from a typical fresh slide section $\left(5 \mu \mathrm{m} \times 1 \mathrm{~cm}^{2}\right)$. The amount of macromolecules extracted from conventional FFPE tissues was about $10-25 \%$ of that from fresh tissues. The experiment indicated that the NDME technique is able to extract both proteins and nucleic acids, and suggested the possibility of selective extraction by modification of buffer components.

Proteins extracted from LN, liver, brain, lung, and prostate showed different band patterns (Figure 2c), suggesting proteins of different types and quantities were extracted from FFPE tissue sections. The extracted proteins contained more low-MW species than high-MW species, but some proteins with MW as high as $188 \mathrm{kDa}$ were extracted, indicating that the NDME extraction method effectively reverses the crosslinkage between macromolecules and formaldehyde. Extending the extraction time would generate a relatively greater amount of high-MW species at the expense of loss of tissue integrity and morphology.

\section{Tissue Morphology is Preserved after NDME Treatment}

What makes the NDME method unique compared to other extraction methods is its ability to preserve tissue morphology after extraction treatment, so that the same tissue section can be used for slide-based 
a

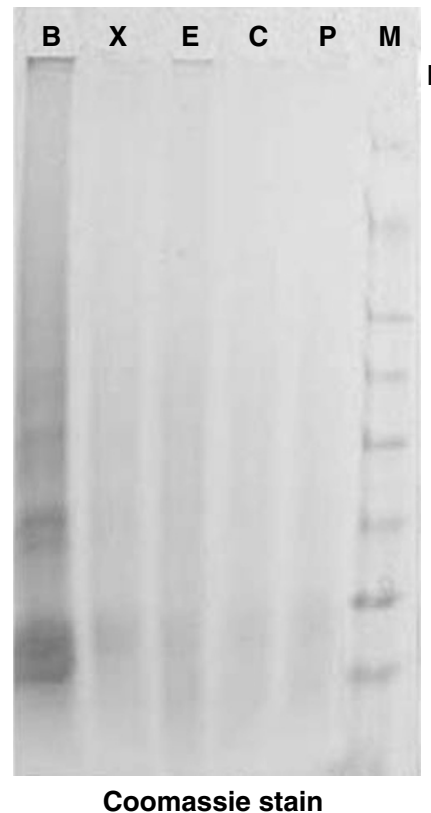

Using various extraction buffers

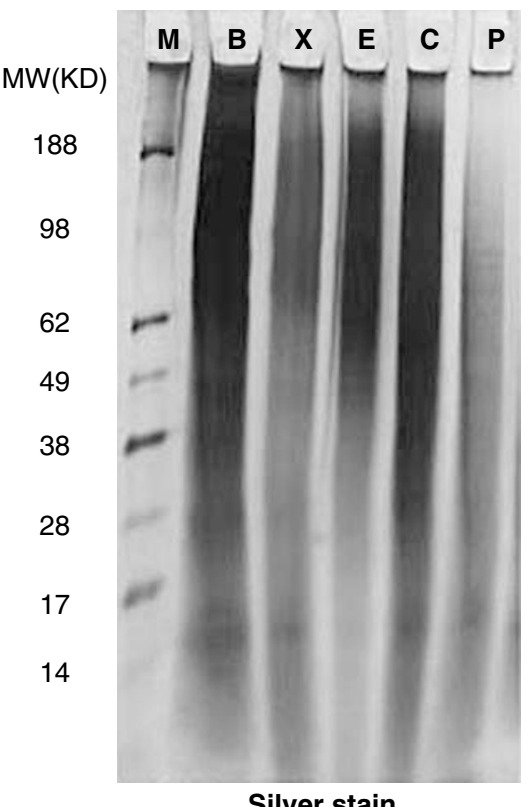

b Frozen or fixed tissues

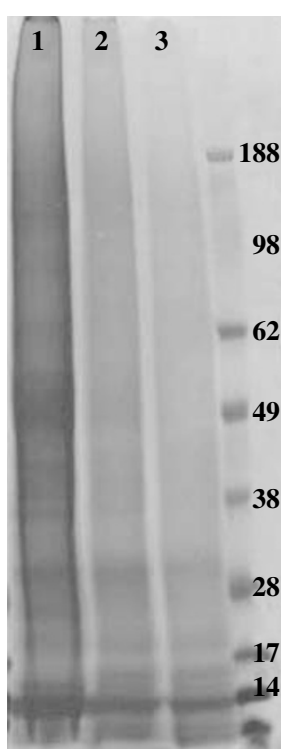

Coomassie stain
C Various tissues

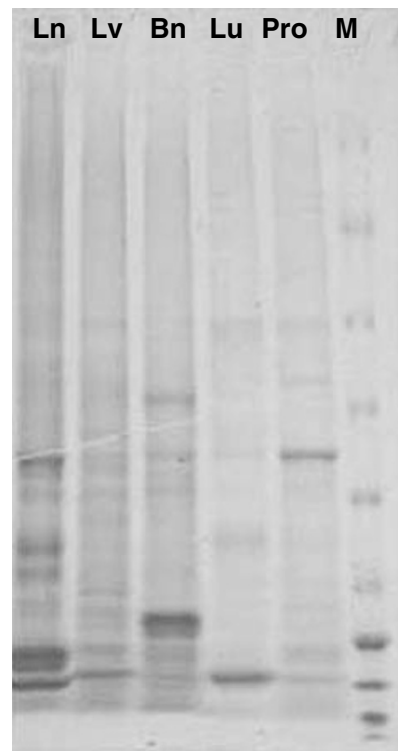

Coomassie stain

Figure 2 Factors affecting the amount of extracted macromolecules by NDME. Total proteins extracted from fresh or FFPE tissue sections by NDME were analyzed by SDS-PAGE. (a) FFPE tonsil tissues were extracted using different buffers: B = FFPE-PE buffer from Bio-Quick; $\mathrm{X}=$ FFPE-NE buffer from Bio-Quick; $\mathrm{E}=0.01 \mathrm{M}$ EDTA; $\mathrm{C}=10 \mathrm{mM}$ citrate; $\mathrm{P}=$ Tissue-PE $\mathrm{LB}$ from Geno Tech; and $\mathrm{M}=$ low-range protein mass marker. (b) Extracts using NDME-PE from lymph node of: $1=$ frozen; $2=$ routine-fixed FFPE; and $3=$ overfixed FFPE. (c) Extracts

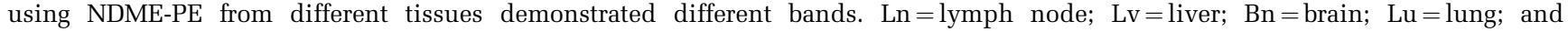
Pro $=$ prostate

morphological and localization studies after extraction. H\&E staining was typically more vivid on tissue sections treated with the NDME, as seen in Figure 3a. Cytoplasmic staining in sections of LN was also enhanced after extraction. Cell-cell space/ gaps seemed to disappear, and individual cells and nuclei swelled slightly, making nucleoli easier to observe under high magnification $(\times 1000)$. Cytoplasmic structures, such as the eosinophilic granules of eosinophils, and nuclear features, such as the speckled chromatin pattern of a plasma cell nucleus, remained intact.

In addition to improved H\&E staining, the NDME actually enhanced IHC staining and removed the need for antigen retrieval. Using anti-CD5 antibody, we performed IHC analysis on consecutive FFPE tissue sections that had undergone the NDME extraction procedure for increasing lengths of time (Figure 3b). Extraction solutions were analyzed on an SDS-PAGE gel (Figure 3c). Without NDME treatment $(0 \mathrm{~min})$, the slide section revealed no visible IHC signal due to severe antigen masking after formalin fixation. Increasing extraction time generated both greater intensity of IHC signals on the slide section and a greater number of extracted molecules. A 5-min incubation in NDME-PE generated few proteins. A greater number of proteins, especially the higher-MW species, were observed in extraction treatments exceeding $20 \mathrm{~min}$. IHC signal increased proportionately with the length of extrac- tion treatment up to $30 \mathrm{~min}$, while tissue morphology remained largely unchanged up to $20 \mathrm{~min}$. Detailed antigen location and morphology were clearly seen. There were noticeable morphologic changes after $30 \mathrm{~min}$ of extraction treatment, as evidenced by the disappearance of blue hematoxylin counterstaining in Figure $3 \mathrm{~b}$, probably due to loss of nuclear structure. This experiment suggests that larger proteins may take longer to release because more crosslinkages need to be reversed. In addition, proteins not at the cutting surface and proteins buried in membrane or cellular particles may need time to redissolve into solutions.

\section{Analysis of Proteins in NDME Extracts and on Tissue Sections after NDME Extraction}

To investigate whether proteins extracted by the NDME procedure retain their integrity (size) and antigenicity, proteins extracted from archived FFPE sections were resolved by SDS-PAGE, transferred to PVDF membrane, and immunoblotted with four antibodies, as shown in Figure 4. All four antibodies recognized their corresponding antigens at the expected size. In panel a, anti-p24, an antibody specific for a $24 \mathrm{kDa}$ HIV capsid protein, detected a band in an HIV $(+) \mathrm{LN}$, but not in an $\operatorname{HIV}(-)$ reactive $\mathrm{LN}$, while a $32 \mathrm{kDa}$ band corresponding to a common membrane glycoprotein of B-lymphocytes 

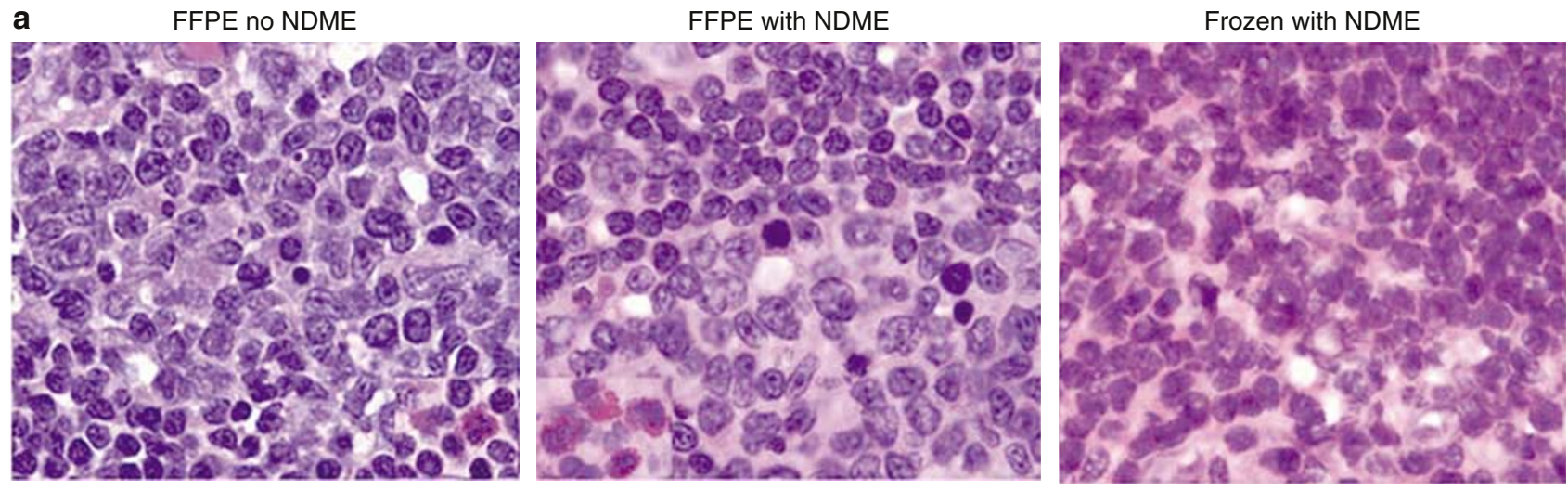

b

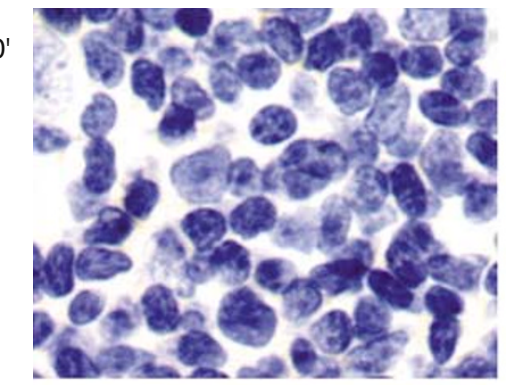

$5^{\prime}$

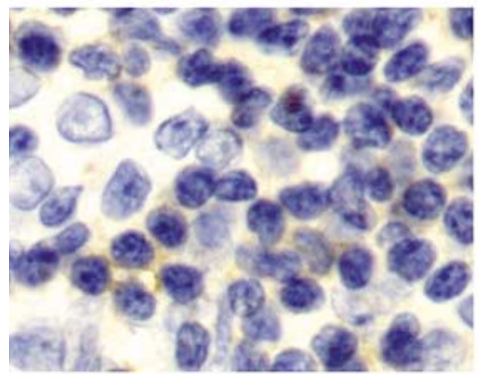

10

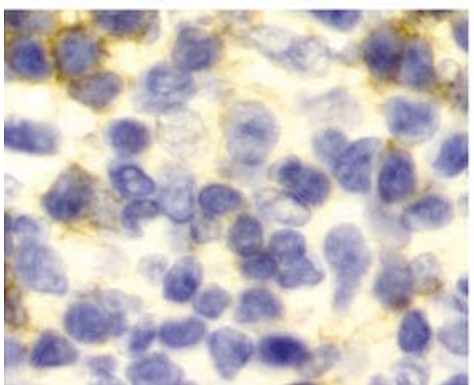

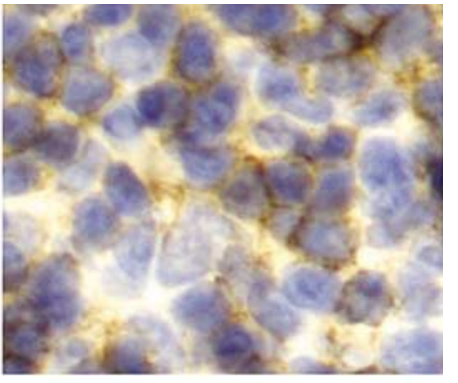
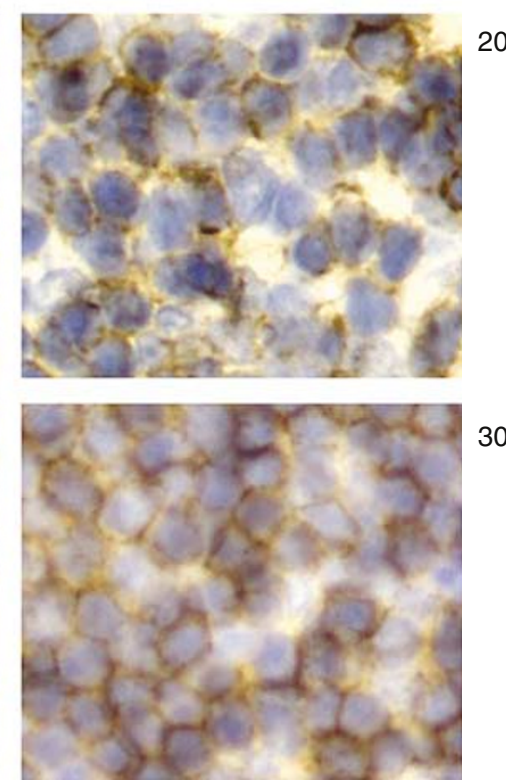

C $15^{\prime}$ $30^{\prime}$
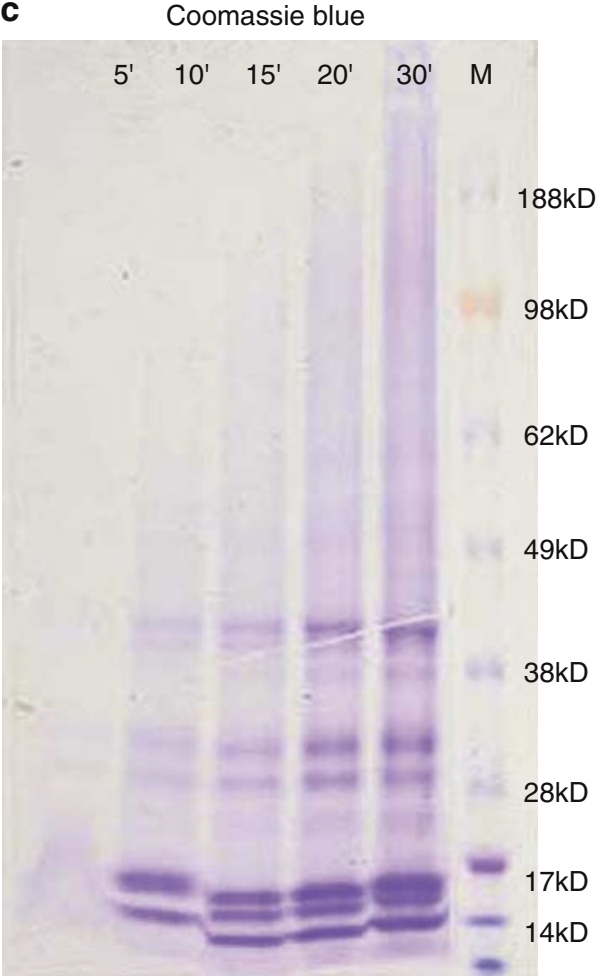

Figure 3 Effect of NDME procedures on tissue morphology and extracted proteins. (a) Comparison of H\&E staining on lymph node sections with and without the NDME procedure. The 20 min NDME on FFPE and 5 min NDME on frozen section did not damage tissue morphology $(\times 1000)$. (b) Comparison of IHC staining against CD5 $(\times 400)$ on FFPE lymph node sections NDME treated with FFPE-PE buffer for $0,5,10,15,20$, and $30 \mathrm{~min}$, respectively. Extended NDME treatment increased the IHC signal but resulted in increased morphological damage. (c) NDME extracts from panel b were analyzed on SDS-PAGE and stained with Coomassie blue. Extended NDME treatment generated more proteins.

was observed in the same extract from reactive LN by anti-CD20, as expected. In panel b, anti-cyclin E detected a $52 \mathrm{kDa}$ common nuclear protein band in extracts from tissues of anaplastic large-cell lymphoma (ALCL) and Burkitt's lymphoma (BL). In contrast, anti-CD30 detected an $85 \mathrm{kDa}$ precursor protein processed in Golgi particles and a mature $120 \mathrm{kDa}$ membrane protein in an ALCL section, as expected, but not in a BL section (panel c). Molecular analysis (Figure 4b) was well correlated with the IHC (Figure 4c) on tissue sections even after the NDME treatment, showing that ALCL expressed both cyclin E (brown stains in nuclei) and CD30 (brown stains in membrane and Golgi region), while BL expressed only cyclin E. Large membrane proteins such as $180 \mathrm{kDa}$ CEA and $220 \mathrm{kDa}$ LCA 
a

$\alpha-C D 20$

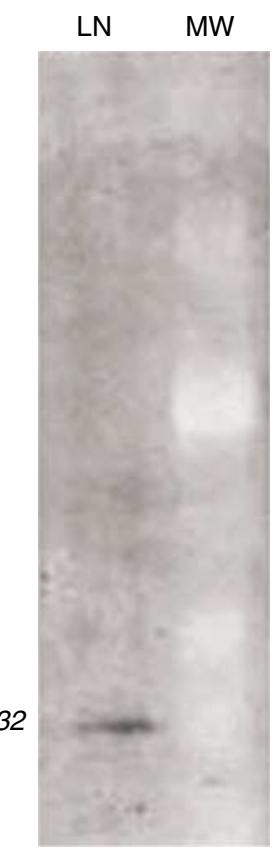

Memberane glycoprotein
(kD)

216

132

78

32

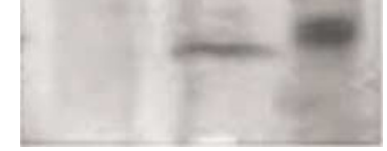

HIV capsid

protein b

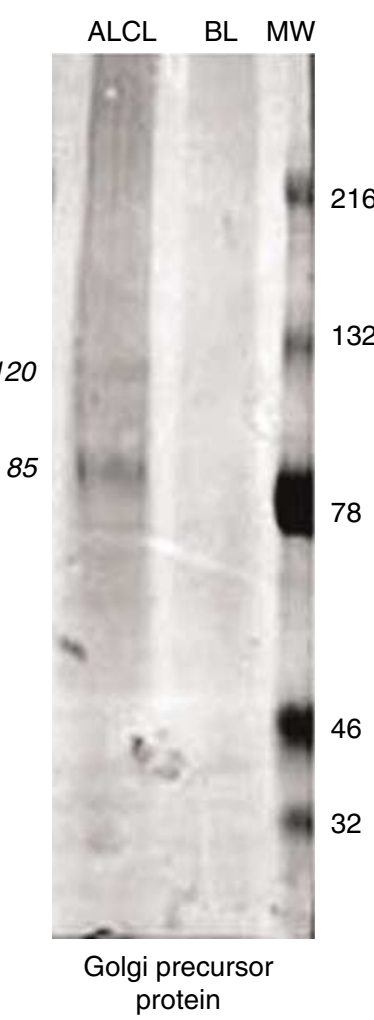

$\alpha$-Cyclin E

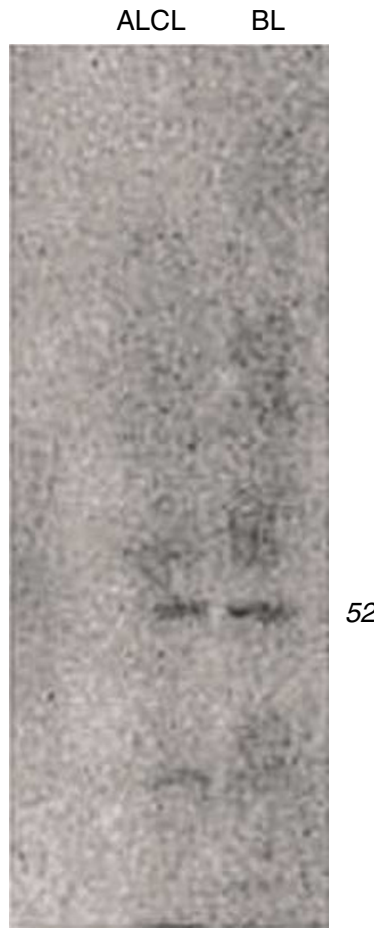

Nuclear protein
C
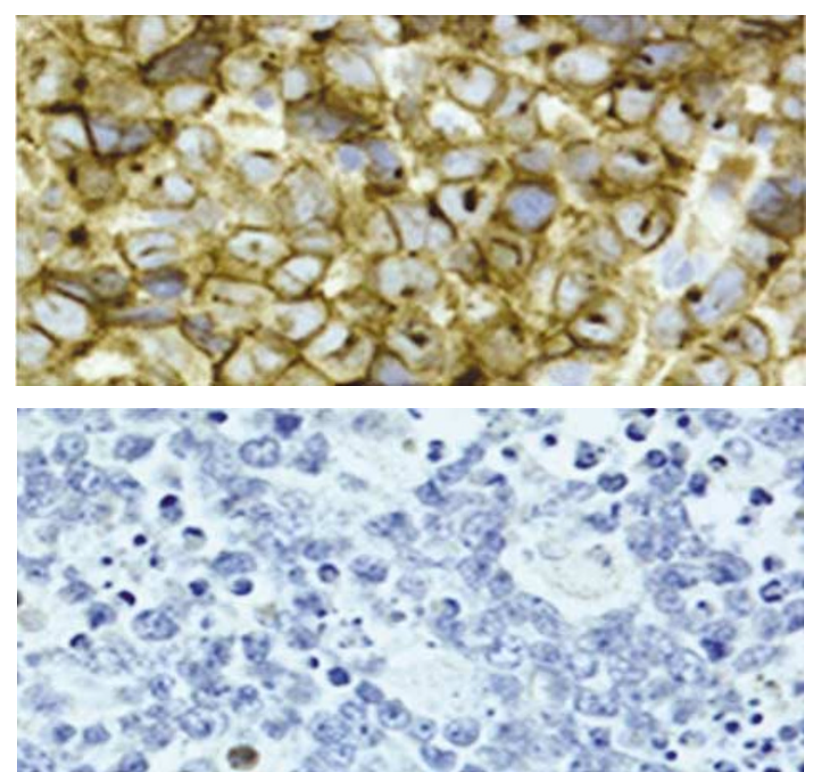

ALCL
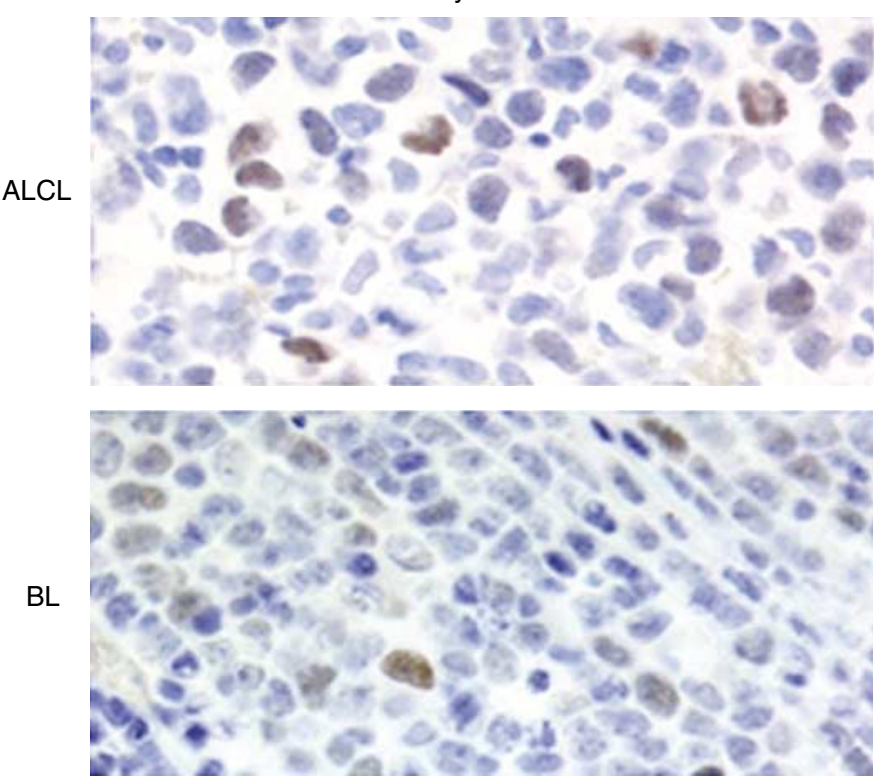

Figure 4 Morphological and molecular diagnoses of FFPE lymph node tissues from patients with AIDS and various lymphomas. (a and b) Western blot of extracts from FFPE sections by NDME, detected with anti-CD20, anti-HIV p24, anti-CD30, and anti-cyclin E. (c) Immunohistochemistry of the ALCL and BL lymph node tissue sections ( $\times 200$, as in panel b) after NDME treatment, showing that ALCL and BL were positive for cyclin E, but only ALCL showed positive CD30 expression. LN = reactive lymph node; HIV $+=$ HIV + AIDS lymph node; ALCL = anaplastic large-cell lymphoma; $\mathrm{BL}=$ Burkitt’s lymphoma.

were extracted by the NDME method (data available). This experiment also demonstrated that molecular analysis provides information on the size(s) and quantity of proteins, while IHC provides details of cellular morphology and the distribution of protein expression. 


\section{Protein Extracts Analyzed by Modern Techniques}

A compelling reason to develop a nondestructive molecule extraction method (NDME) is to combine classic pathological diagnosis with the more technologically advanced protein biochip techniques and protein profiling, such as protein arrays and SELDI-TOF MS. ${ }^{17}$ Proteins extracted from various tissues by the NDME procedure were two-fold sequentially diluted with NDME-PE and applied onto nitrocellulose-coated glass slides to make reverse-phase protein lysate microarrays ${ }^{18}$ (Figure 5). Compared to the extract from frozen tissue (No. 1), a substantial amount of total proteins were extracted from either ethanol- (No. 3) or formalin-fixed (remaining samples) tissues. While common keratin proteins were observable in various tissue types, prostate-specific proteins, PSA and PAP were almost exclusively expressed in all three prostate tissues (Nos. 8-10).

Figure 6 shows the SELDI-TOF MS spectra of proteins extracted from FFPE tissue sections by the NDME technique. Protein extracts from FFPE sections were enriched and desalted by binding to a commercially available hydrophobic reverse-phase protein chip. The bound proteins were then analyzed by SELDI-TOF MS. The overall profile of proteins extracted from FFPE tissue and frozen tissue was clearly quite similar. This observation held true for the spectra showing low mass/charge $(\mathrm{m} / \mathrm{z}$ ) range and $10-21 \mathrm{~K}$ high $\mathrm{m} / \mathrm{z}$ range (Figure $6 \mathrm{a}$ ). Buffer components affect not only the type and amount of molecules to be extracted from tissue sections (Figure 2) but also the binding affinity and selectivity of the protein chip, demonstrating that protein profiles are more significantly affected by the type of extraction buffer used than by how the tissue is preserved. Obviously, more systematic study is needed to find buffers that will produce similar protein profiles in fresh and variously fixed tissues. Nevertheless, Figures 6 indicates that the NDME technology can extract a high quantity and full spectrum of proteins compatible with modern techniques for molecular analysis, such as protein arrays and mass spectrometry.

\section{Sensitivity and Specificity of NDME Method}

The NDME is highly efficient. Sufficient proteins can be extracted from a tissue section of $3 \mathrm{~mm}^{2}$ for less sensitive Western blot gel analysis. As shown in Figure 7, an FFPE tissue section microdissected to $1.5 \times 2 \mathrm{~mm}^{2}$ generated enough signal to show a specific ER band on Western blot, even though a very small amount of total proteins was visible in comparison to other normal-sized sections. No ER band was detected for Case 2, which was ER negative. The slide sections were used for further morphological immunochemical evaluations after the NDME extraction. Case 1 was of Her-2(+) and ER(-) breast carcinoma. Most glands were neoplastic and positive for Her-2 (Figure 7c); normal glands were ER positive and neoplastic glands were ER negative. That was why on the Western blot the ER band of extract from Case 1 breast carcinoma was not as strong as the one from Case $3 \mathrm{ER}(+)$. Furthermore, NDME extract from 5000 to 6000 cells of neoplastic and benign epithelial prostate selected by laser capture microdissection showed PAS, PAP, and AMACR by Western blot (data available). These results demonstrate that the NDME technology was efficient and specific enough to allow selective protein analysis and profiling after microdissection.

\section{Analysis of DNA/RNA in NDME Extracts and on Tissue Sections after Extraction}

DNA and RNA of good quality and integrity were extracted by the NDME technology and directly used in downstream PCR and RT-PCR amplification (Figure 8). Quantitative study indicated that the amount of mRNA extracted from FFPE was less than $50 \%$ of that from frozen tissue, depending on how well the RNA was preserved during the tissue 
$400-1,500 \mathrm{~m} / \mathrm{z}$

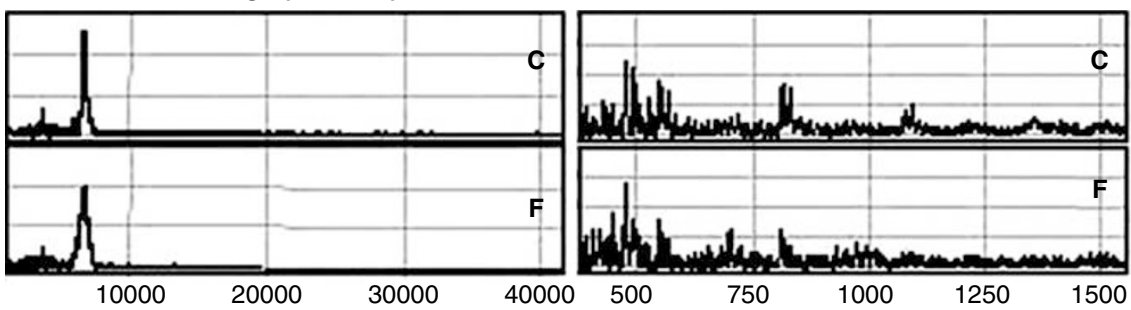

$10 \mathrm{k}-21 \mathrm{k} \mathrm{m} / \mathrm{z}$

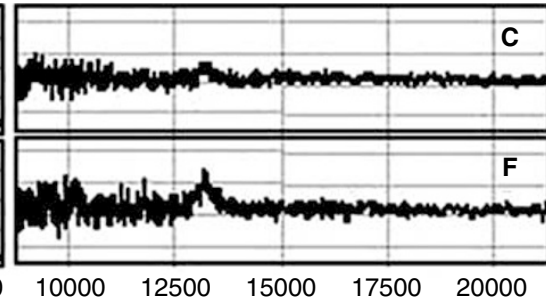

b

Comparison of SELDI-TOF spectra of proteins extracted using different buffers
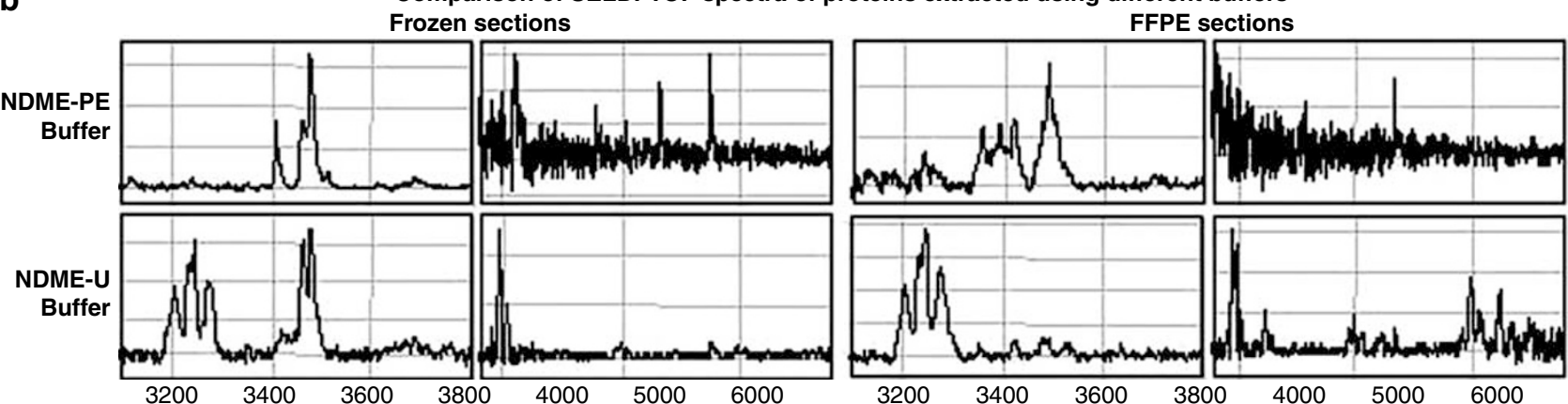

Figure 6 The NDME technology supports protein profiling by SELDI-TOF MS. (a) Protein profiles of FFPE tissue resemble those of frozen tissue. Proteins extracted by NDME-PE were selected with a hydrophobic reverse-phase protein chip and analyzed with PBS-II SELDITOF MS with software provided by the manufacturer. C: Frozen tissue section; F: FFPE tissue section. (b) Protein profiles of frozen vs FFPE pancreas sections were greatly affected by tissue fixation methods and the extraction buffers used.

a

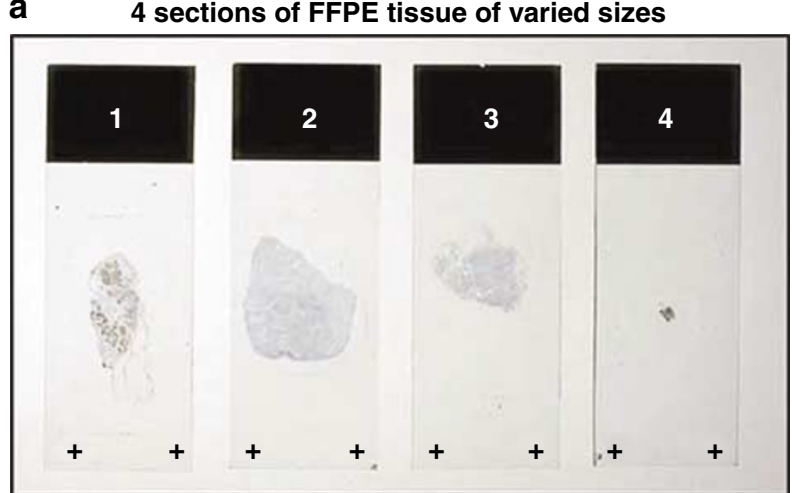

b Extracted proteins from a $\begin{array}{lllll}1 & 2 & 3 & 4 & M\end{array}$

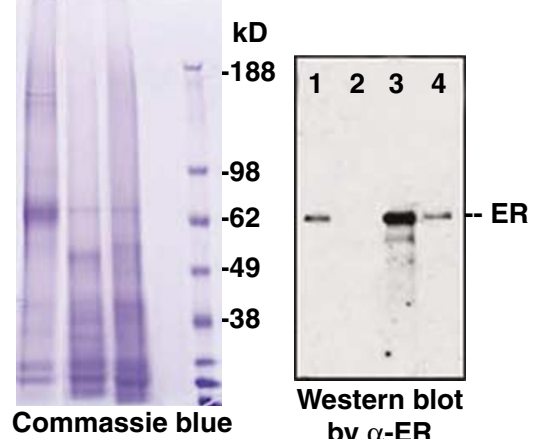

C

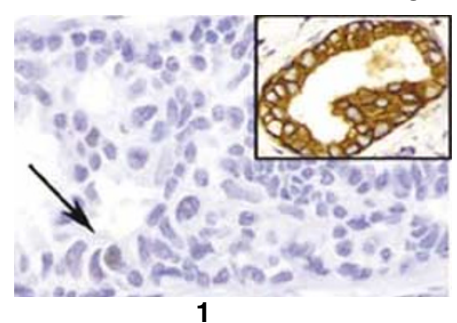

IHC with $\alpha$-ER antibody on the 4 tissue sections after the NDME extraction

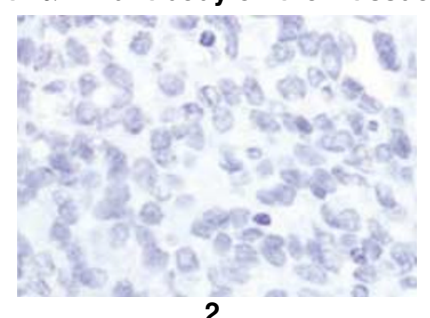

2

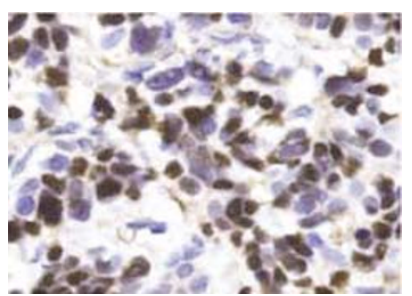

3

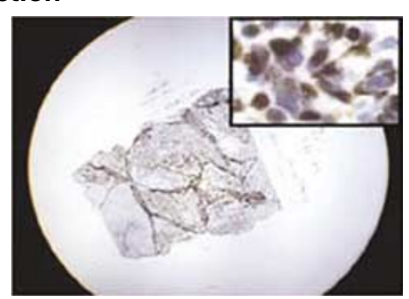

Figure 7 Gel electrophoresis and histological analyses of four FFPE tissue specimens. (a) Tissue sections left on the slide after the NDME extraction of Case $1=\operatorname{Her}-2(+)$ and $\operatorname{ER}(-)$ breast carcinoma; Case $2=\mathrm{ER}(-)$ endometrial stromal sarcoma; Case $3=\mathrm{ER}(+)$ breast carcinoma; and Case $4=$ dissection of case $3\left(\sim 1.5 \times 2 \mathrm{~mm}^{2}\right)$. (b) Analyses of the total proteins and ER-specific protein in the NDME extracts. (c) IHC with anti-ER antibody on tissue sections after the NDME extraction. The arrow in C1 indicates one residue of the ER( + ) benign gland. The inset in C1 is IHC with anti-Her-2 antibody. C4: microscopic view of section 4 under $\times 20$ and $\times 400$ magnification.

fixation process. Using the NDME technique, extracts from a single section of 30-year-old archived FFPE retinal tissue generated RT-PCR products
$367 \mathrm{bp}$ long in four out of six samples (lanes $2-7$ in Figure 8a). PCR products of $1309 \mathrm{bp}$ were similarly obtained from tissue extracts (Figure 8c). Further- 
a

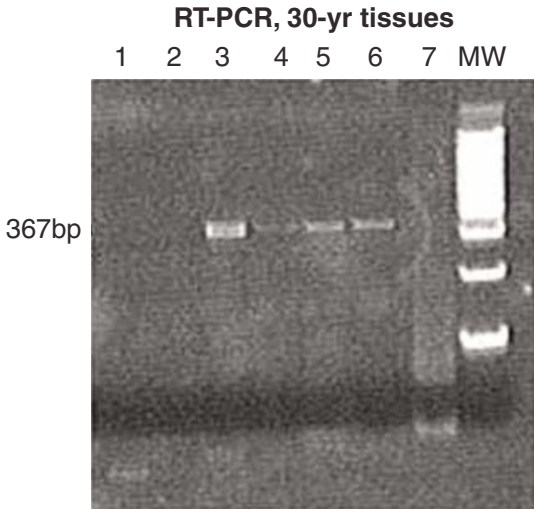

C PCR, frozen \& fixed tissues

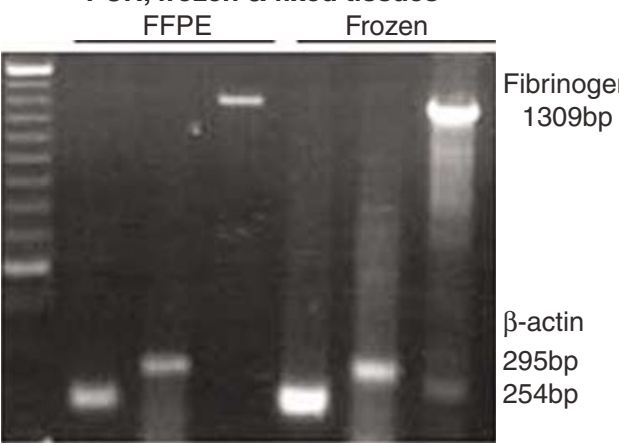

b

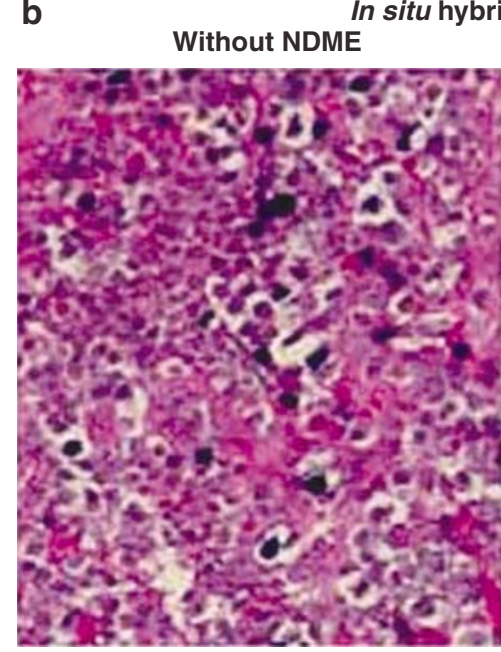

In situ hybridization (ISH)

With NDME

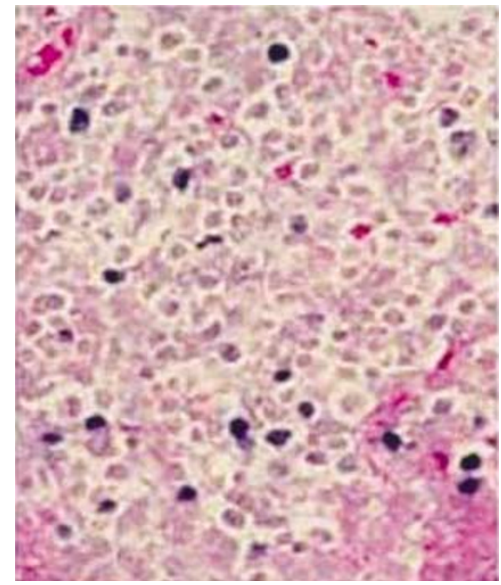

Chromagenic in situ hybridization (CISH)

With NDME
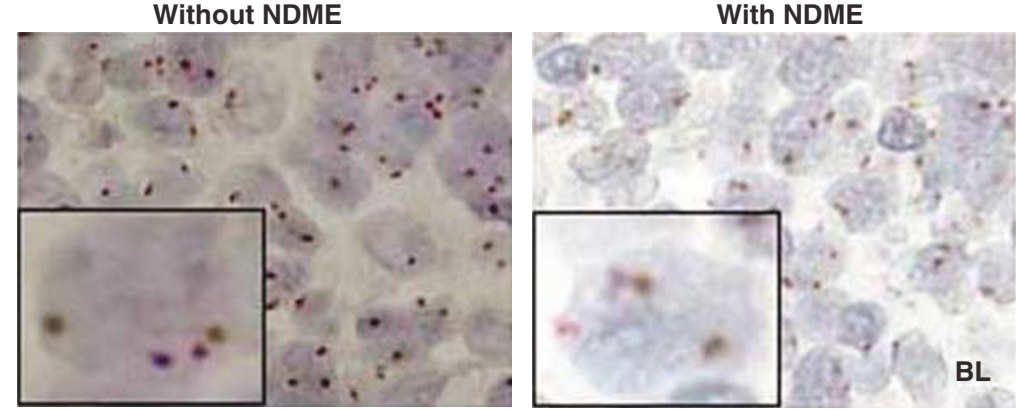

Figure 8 Analyses of nucleic acids in the NDME extracts and on slide sections with and without NDME treatment. (a) RNA was extracted from 30-year-old archived FFPE retinal sections, generating amplicons of over $300 \mathrm{bp}$. RT-PCR amplification was performed using tissue extracts from six different retinal samples (lanes 2-7, negative control in lane 1) in FFPE-NE buffer, followed by DNase treatment with primers for actin protein of $367 \mathrm{bp} . \mathrm{M}=100 \mathrm{bp}$ DNA ladder. (b) RNA-ISH of consecutive sections of lymph node with infectious mononucleosis $(\times 200)$. The blue staining shows the results of Epstein-Barr virus-early RNA (EBER) hybridization before and after NDME treatment. (c) PCR of NDME extracts from FFPE and frozen tissue sections generated DNA fragments of over $1300 \mathrm{bp}$. (d) CISH detection of the c-Myc translocation $(\times 1000)$ in Burkitt's lymphoma tissue sections before and after NDME treatment.

more, as shown in Figures 8b and d, tissue sections after NDME treatment could be used for slide-based localization analysis, such as RNA-ISH (BioGenex, San Ramon, CA, USA) and CISH (Zymed Inc., South San Francisco, CA, USA). Following the NDME procedure, tissue sections could still provide sufficient morphologic detail and good hybridization signals. Blue staining (Figure 8b) revealed the location of Epstein-Barr virus-early RNA on consecutive sections of LN with infectious mononucleosis. There was no detectable difference in hybridization pattern and intensity before and after NDME treatment, but there was a decrease in counterstaining intensity following NDME. Likewise, clear c-Myc translocation was obvious in BL tissue sections before and after NDME.

\section{Discussion}

We have demonstrated that NDME technology not only extracts enough soluble proteins, DNA, and
RNA from a single fresh frozen or FFPE $\mathrm{H}+\mathrm{E}$ or unstained tissue section for molecular detection, such as SDS-PAGE, Western blot, and RT-PCR, but also maintains the integrity of tissue morphology, protein antigenicity, and intact chromosomal structures after extraction. Thus, this technology provides a useful means to obtain and compare both histological and molecular diagnosis on a single tissue section.

Many question the feasibility of extracting molecules from intact slide sections, because all conventional extraction methods require homogenization of fresh or fixed tissues. We believe that the thickness of the slide sections $(3-5 \mu \mathrm{m})$ is critical to facilitation of molecule extraction. Tissue sectioning actually cuts through most cells and exposes cellular and nuclear contents to contact solutions. As demonstrated by our experimental results, the extraction duration, preservation method, temperature, and composition of the extraction buffer all have an impact on the quantity and quality of protein and nucleic acids extracted from frozen and 
fixed tissue sections using the NDME method. So far, we have found that NDME-PE buffer is more efficient for protein extraction than NDME-NE buffer or other buffers, including common antigen retrieval buffers and one commercially available buffer. The composition of NDME buffer needs to be compatible with the downstream molecular analysis, such as SDS-PAGE, high-pressure liquid chromatography, MS, and protein-binding biochip arrays. Although further study is needed for mass spectral protein profiling and actual protein identifications using NDME extracts, a recent publication indicates that destructively extracted solutions from FFPE tissues can be used for proteomic investigation on a variety of mass spectrometry platforms. ${ }^{19}$

Different applications may require different extraction conditions, requiring variation of the extraction buffer composition, or variation of the duration and/or intensity of the microwave or ultrasound treatments. Variation of these parameters may allow selective macromolecular release. While high abundant proteins tend to give high yield in the extracts, the relative amount of proteins in the extracts is not correspondent directly to that in the actual cellular contents. As shown in Figure 4a, although the HIV capsid protein p24 was much less abundant compared to a common membrane protein CD20, the amount of these two proteins in the NDME extract were similar due to the low extractable efficiency of membrane proteins in general. This problem exists even in destructive extraction methods. Using reagents to enhance the solubility of hydrophobic proteins may help in extracting membrane proteins, but we need to avoid using reagents that interfere with subsequent electrophoresis or MS detection. Usually, low abundant proteins detectable by IHC staining can be detected in the NDME extract by gel electrophoresis-Western blot using the same antibody as long as there are enough such protein-containing cells. IHC detection is based on localized detection at cellular level, while gel-based Western blotting requires pooling and concentrating proteins extracted from many cells. In Figure 7, Case 1 belonged to the type of Her-2(+) and ER(-) breast carcinoma. The scattered epithelial cells of residue benign lobule, account for less than $5 \%$ total cells in Case 1, showed very weak ER( + ) staining compared to the strong positive staining (brown color) in Case 3 , which belonged to the type of $\mathrm{ER}(+)$ breast carcinoma. Yet, the ER in Case 1, of very low abundance in terms of both the low cellular expressing copy and the low percentage of cells that express the protein, was detected in the NDME extract from a single tissue section.

A proper extraction buffer is the one that partially dissolves macromolecules in about 20-30 min at high temperature without disrupting the general tissue architecture of FFPE samples. For instance, NDME with $0.01 \mathrm{~N} \mathrm{NaOH}$ as an extraction buffer causes nuclear dissolution and significant cell swelling. Tissue sections after NDME treatment using $0.01 \mathrm{~N} \mathrm{NaOH}$ or $0.01 \mathrm{~N} \mathrm{HCl}$ result in almost no IHC signal and yet only moderate amount of protein by gel electrophoresis. This indicates that low IHC staining does not necessarily equate to a high amount of protein extraction, and vice versa. As shown in Figure 3, NDME-PE buffer causes both increased IHC staining and the amount of extracted total proteins within $30 \mathrm{~min}$. Usually, tissue sections after 20-30 min NDME treatment generated stronger IHC staining than that after conventional antigen retrieval treatment. Extended NDME treatment will cause distortion of tissue architecture such as peeling of tissue off the slides or tissue swelling and dissolution of cellular detail.

It is commonly thought that FFPE tissues cannot be used for high-throughput analysis due to formalin-induced macromolecule crosslinking. However, it has long been known that protein crosslinkage by formalin is reversible ${ }^{20}$ and that the crosslinking that occurs during formalin fixation retains the secondary structure present in fresh tissue. ${ }^{21}$ The discovery of crosslinking reversion by heating treatment led to the development of antigen retrieval techniques in $1991 .^{22}$ So far, the mechanisms of crosslinking reversal as the base for antigen retrieval are not well understood. ${ }^{23-25}$ Elucidation of these mechanisms will be very helpful for optimization of macromolecular extraction. Current methods for antigen retrieval include proteinase predigestion, ${ }^{26}$ chemical pretreatment, ${ }^{27-28}$ and heat-induced epitope retrieval. ${ }^{22-23}$ For the purpose of nondestructive extraction to maintain the original morphology and the integrity of macromolecules, we exclude proteinase digestion but combine both heating and mild chemical treatment in the NDME procedures.

We found that approximately $20 \mathrm{~min}$ of heating was absolutely necessary for FFPE sections to release proteins and nucleic acids for molecular analyses. In contrast, merely adding extraction buffer to fresh frozen tissue sections without heating was enough to release proteins and nucleic acids for SDS-PAGE and PCR amplification (Figures 2b, 3a, and 8c). Recently, there is increasing evidence that formalin-induced macromolecule crosslinking can be reversed under high temperature. ${ }^{29-31}$ Heating treatment not only transformed intermolecular cross-linked polymers into monomers ${ }^{24,29,30}$ but also partially restored enzymatic reactivity of formalinfixed RNase $\mathrm{A}^{31}$ Based on literature and our observations, we believe that heating effect, either direct heating as described herein or microwave/ ultrasound-induced heating, plays a pivotal role in the NDME procedures for FFPE tissues. The NDME procedure facilitates macromolecule extraction from fixed tissues in three ways: (1) reversal of crosslinking, (2) solubilization of non-crosslinked molecules into buffer, and (3) stabilization of extracted molecules in the buffer. As depicted in Figure 9, we propose that the NDME process induces release of macromolecules from the exposed side of a tissue section that is immersed in extraction buffer. 

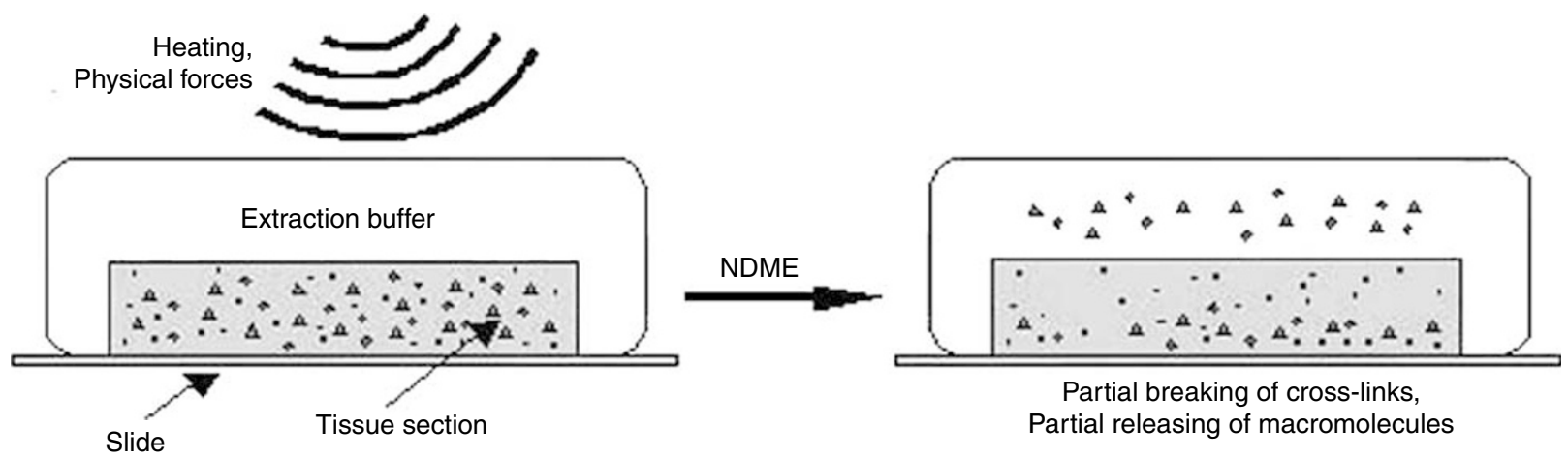

Figure 9 Working hypothesis of the mechanism of NDME technology.

Heating and the optional implementation of microwave and ultrasound energy facilitate the reversal of crosslinking and the penetration of buffer into the tissue, allowing the release of dissolvable macromolecules into the extraction buffer.

In our study, the level of formalin fixation varied substantially from sample to sample because processing of surgical samples could not be adequately controlled. In general, the longer the NDME procedure, the more macromolecules are released, and the more tissue morphology is altered. Overfixed tissue may require longer heating, while fresh tissue does not need heating. In routine practice, surgical tissue samples are fixed in formalin overnight and then processed with graded alcohol, xylene, and paraffin for another 12-20 h. However, in some cases, tissues are left in formalin for as long as $48 \mathrm{~h}$. It is well known that antigen retrieval may be difficult in overfixed samples even after prolonged pretreatment. In future studies, we will determine whether proteins are extractable from tissues fixed for a longer-than-normal amount of time and determine the best possible fixation time for simultaneous histological analysis and protein extraction and downstream analyses. In addition, we will also determine the optimal intensities and durations of ultrasound and microwave treatments, as well as optimal processing conditions $(\mathrm{pH}$, temperature, and buffer composition) for tissue sections of various types fixed by different methods, including snap-frozen samples. We will further test the possibility of selective or specific componentenrichment extraction by applying different types of physical forces or buffer to achieve the best extraction efficiency without destruction of tissue morphology.

\section{Acknowledgements}

We extend our sincere thanks to Bonnie L Casey for her excellent editorial assistance in the preparation of this manuscript. This work was supported in part by NIH/NCI Grant 1R21 CA091166-01A1 (to W-SC) and by ARP/AFIP Grant (UBKL) (to W-SC). The opinions expressed in this article are the personal views of the authors and are not to be construed as representing the views of the Department of the Army or the Department of Defense.

\section{References}

1 Marte B (ed). Nature insight: proteomics. Nature 2003;422(Suppl):191-237.

2 Liotta L, Petricoin E. Molecular profiling of human cancer. Nat Rev Genet 2000;1:48-56.

3 Emmert-Buck MR, Strausberg RL, Krizman DB, et al. Molecular profiling of clinical tissue specimens: feasibility and applications. Am J Pathol 2000;156: 1109-1115.

4 Clark RK, Damjanov I. Immunoblotting of keratin polypeptides extracted from tissues preserved in standard histologic fixatives. J Histochem Cytochem 1986;34:679-682.

5 Conti CJ, Larcher F, Chesner J, et al. Polyacrylamide gel electrophoresis and immunoblotting of proteins extracted from paraffin-embedded tissue sections. J Histochem Cytochem 1988;36:547-550.

6 Ikeda K, Monden T, Kanoh T, et al. Extraction and analysis of diagnostically useful proteins from formalin-fixed, paraffin-embedded tissue sections. J Histochem Cytochem 1998;46:397-403.

7 Gillespie JW, Best CJ, Bichsel VE, et al. Evaluation of non-formalin tissue fixation for molecular profiling studies. Am J Pathol 2002;160:449-457.

8 Shibutani M, Uneyama C, Miyazaki K, et al. Methacarn fixation: a novel tool for analysis of gene expressions in paraffin-embedded tissue specimens. Lab Invest 2000; 80:199-208.

9 von Weizsacker F, Labeit S, Koch HK, et al. A simple and rapid method for the detection of RNA in formalinfixed, paraffin-embedded tissues by PCR amplification. Biochem Biophys Res Commun 1991;174: 176-180.

10 Neubauer A, Neubauer B, He M, et al. Analysis of gene amplification in archival tissue by differential polymerase chain reaction. Oncogene 1992;7:1019-1025.

11 Krafft AE, Duncan BW, Bijwaard KE, et al. Optimization of the isolation and amplification of RNA from formalin-fixed, paraffin-embedded tissue: the Armed Forces Institute of Pathology experience and literature review. Mol Diagn 1997;2:217-230.

12 Byers R, Roebuck J, Sakhinia E, et al. PolyA PCR amplification of cDNA from RNA extracted from 
formalin-fixed paraffin-embedded tissue. Diagn Mol Pathol 2004;13:144-150.

13 Izawa $\mathrm{H}$, Yamamoto $\mathrm{H}$, Ikeda $\mathrm{M}$, et al. Analysis of cyclin D1 and CDK expression in colonic polyps containing neoplastic foci: a study of proteins extracted from paraffin sections. Oncol Rep 2002;9: 1313-1318.

14 Yazaki M, Liepnieks JJ, Callaghan J, et al. Chemical characterization of a lambda I amyloid protein isolated from formalin-fixed and paraffin-embedded tissue sections. Amyloid 2004;11:50-55.

15 Murphy CL, Eulitz M, Hrncic R, et al. Chemical typing of amyloid protein contained in formalin-fixed paraffin-embedded biopsy specimens. Am J Clin Pathol 2001;116:135-142.

16 Paweletz CP, Charboneau L, Bichsel VE, et al. Reverse phase protein microarrays which capture disease progression show activation of pro-survival pathways at the cancer invasion front. Oncogene 2001;20:1981-1989.

17 Fetsch PA, Simone NL, Bryant-Greenwood PK, et al. Proteomic evaluation of archival cytologic material using SELDI affinity mass spectrometry: potential for diagnostic applications. Am J Clin Pathol 2002;118: 870-876.

18 Petricoin EF, Ardekani AM, Hitt BA, et al. Use of proteomic patterns in serum to identify ovarian cancer. Lancet 2002;359:572-577.

19 Prieto DA, Hood BL, Darfler MM, et al. Liquid tissue: proteomic profiling of formalin-fixed tissues. BioTechniques 2005;38:32-35.

20 Jackson V. Studies on histone organization in the nucleosome using formaldehyde as a reversible crosslinking agent. Cell 1978;15:945-954.

21 Mason JT, O’Leary TJ. Effects of formaldehyde fixation on protein secondary structure: a calorimetric and infrared spectroscopic investigation. J Histochem Cytochem 1991;39:225-229.
22 Shi SR, Key ME, Kalra KL. Antigen retrieval in formalin-fixed, paraffin-embedded tissues: an enhancement method for immunohistochemical staining based on microwave oven heating of tissue sections. J Histochem Cytochem 1991;39:741-748.

23 Shi SR, Cote RJ, Taylor CR. Antigen retrieval techniques: current perspectives. J Histochem Cytochem. 2001;49:931-937.

24 Yamashita S, Okada Y. Mechanisms of heat-induced antigen retrieval: analyses in vitro employing SDSPAGE and immunohistochemistry. J Histochem Cytochem 2005;53:13-21.

25 Sompuram SR, Vani K, Messana E, et al. A molecular mechanism of formalin fixation and antigen retrieval. Am J Clin Pathol 2004;122:154-155.

26 Huang SN. Immunohistochemical demonstration of hepatitis B core and surface antigens in paraffin sections. Lab Invest 1975;33:88-95.

27 Kitamoto T, Ogomori K, Tateishi J, et al. Formic acid pretreatment enhances immunostaining of cerebral and systemic amyloids. Lab Invest 1987;57:230-236.

28 Hausen P, Dreyer C. Urea reactivates antigens in paraffin sections for immunofluorescent staining. Stain Technol 1982;57:321-324.

29 Namimatsu S, Ghazizadeh M, Sugisaki Y. Reversing the effects of formalin fixation with citraconic anhydride and heat: a universal antigen retrieval method. J Histochem Cytochem 2005;53:3-11.

30 Rait VK, Xu L, O'Leary TJ, et al. Modeling formalin fixation and antigen retrieval with bovine pancreatic ribonuclease A. II. Interrelationship of cross-linking, immunoreactivity, and heat treatment. Lab Invest 2004;84:300-306.

31 Rait VK, O’Leary TJ, Mason JT. Modeling formalin fixation and antigen retrieval with bovine pancreatic ribonuclease A: I. Structural and functional alterations. Lab Invest 2004;84:292-299. 